\title{
Multiple Levels of Metacognition: Circumstances Interfering With Students' Spontaneous Metacognitive Activities
}

\author{
Young Rae Kim \\ Texas A\&M University-San Antonio \\ Tamara J. Moore \\ Purdue University
}

\begin{abstract}
A theoretical model of metacognition in complex modeling activities has been developed based on existing frameworks, by synthesizing the reconceptualization of metacognition at multiple levels by looking at the three sources that trigger metacognition. Using the theoretical model as a framework, this multiple-case study explores students' spontaneous metacognitive activities while they collaboratively solve complex mathematical modeling tasks. This study used a series of model-eliciting activities-a type of problem-solving activity in which participants are required to verbalize their thoughts while working within a group-as an authentic method for analyzing verbal metacognitive actions. This study identified the circumstances facilitating or interfering with students' spontaneous metacognitive activities. The findings of the study enrich our understanding of how to design metacognitive learning environments. The current study has the potential to guide teachers, teacher educators, and curriculum developers to create circumstances that support students' spontaneous development of metacognitive abilities. It also has the potential to guide the development of effective instructional methods to integrate these circumstances into existing curricula.
\end{abstract}

Keywords: metacognition, spontaneous metacognitive activities, model-eliciting activities

\section{Introduction}

The need and rationale for studying metacognition have been widely advocated, based on the view that metacognition is a major aspect of successful learning (e.g., Bransford, Brown, \& Cocking, 2000; Campione, Brown, \& Connell, 1989). In particular, success in mathematical problem solving and reasoning, which centers on current visions for the effective teaching and learning of mathematics (National Council of Teachers of Mathematics, 2000), has been linked to the critical role of metacognition (Muir, Beswick, \& Williamson, 2008; Schoenfeld, 1987; Schraw, 1998). There also has been considerable research supporting the positive relationship between metacognition and mathematics achievements (e.g., Bayat \& Tarmizi, 2010; Bonnett, Yuill, \& Carr, 2017; Callan, Marchant, Finch, \& German; 2016; Özcan, 2016; Sahin \& Kendir, 2013).

However, most studies fail to go beyond a description of metacognitive behaviors to directly link them with students' improved future outcomes. Lesh and Zawojewski (2007) argued that this limitation is due to the view of metacognition and cognition as hierarchically separate and the lack of regard for the social, contextual, and situated nature of metacognition. They suggested the need for the application of developmental perspectives to metacognition, similar to studies on children's conceptual development. Such an application can provide a window into the development of students' metacognitive abilities - a mechanism making it possible to organize, monitor, and regulate what 
one knows to successfully attain a goal (Lesh \& Zawojewski, 2007; Schoenfeld, 1992). Thus, it can ultimately inform school practice.

\section{A Theoretical Model of Metacognition on Multiple Levels}

In a pilot study, we identified how one student's interactions with a given problem (environmental level) and with others (social level) became a catalyst for thinking metacognitively (Kim, Park, Moore, \& Varma, 2013). The pilot study, which provided the foundation for the current study, led to the development of a theoretical model of metacognition to address the issue and challenge for research on metacognition, as briefly described earlier. We reconceptualized metacognition at multiple levels by looking at three of the sources that trigger metacognition: (a) oneself (the individual level); (b) one's interactions with others (the social level); or (c) one's interactions with learning environments, such as textbooks and computers (the environmental level; Kim et al., 2013). This theoretical model clarifies the distinction between cognitive (i.e., "thinking with" cognitive components) and metacognitive (i.e., "thinking about" cognitive components) behaviors (e.g., Lesh, Lester, \& Hjalmarson, 2003).

Through a single case study, we illustrated how the theoretical model was used to study students' metacognition (Kim et al., 2013). However, multiple-case studies involving a series of problems and several student groups are required to examine the appropriateness and soundness of the theoretical model for research in metacognition. Furthermore, the need to apply developmental perspectives to metacognition research (Lesh \& Zawojewski, 2007), and the need for an in-depth investigation of how an individual's thinking becomes metacognitive within a context by using robust theories (Schoenfeld, 1999) led to the justification for the current study.

\section{The Purpose of the Study}

By employing the theoretical model of metacognition on multiple levels as a framework, the current study conducted a developmental investigation to identify circumstances facilitating or interfering with students' spontaneous metacognitive activities. The primary research question guiding this study is this:

Research Question: What are the circumstances in which metacognitive activity is interfered with at the social and environmental levels?

To address this question, a multiple-case study was employed. This study used a series of modeleliciting activities (MEAs) - a type of problem-solving activity in which students generate mathematical models to solve them - to generate qualitative data from the multiple-case studies of 23 students in seven groups of three to four seventh-grade students, collaboratively working on three different problem-solving sessions for the school year.

\section{Review of the Literature}

\section{Research on Metacognition}

Research studies have successfully provided empirical evidence for metacognitive behaviors during problem solving (e.g., Bonnett et al., 2017; Goos, 2002; Goos, Galbraith, \& Renshaw, 2002; Magiera \& Zawojewski, 2011; Radmehr \& Drake, 2017). For example, Magiera and Zawojewski (2011) extended a methodology for studying students' metacognitive activity during individual problem solving to study students' metacognitive activity during collaborative problem solving, namely 
MEAs. Based on this extension, they found a predominance of students' metacognitive activities, which were "social-based," compared to "self-based" ones.

However, research on metacognition has still made little progress and has had little impact on school practice (Alzahrani, 2017; Lesh \& Zawojewski, 2007), not only because of difficulties related to studying metacognition, but also because of its lack of a theoretical base. In particular, the lack of its impact on school practice is due to the view of metacognition and cognition as hierarchically separate entities (Lesh \& Zawojewski, 2007).

In addition, most researchers have assumed that specific metacognitive functions are always productive, regardless of the stages of problem solving, specific content and contexts. These assumptions result in few studies based on developmental perspectives, which investigate a direct link between instruction in metacognition to the teaching of mathematics and improved problemsolving performance. They also result in a disregard for the social, contextual and situated nature of metacognition (Lesh et al., 2003; Lesh \& Zawojewski, 2007). For example, many educators and researchers' priority may be the development of students' cognitive abilities. They may consider the development of students' metacognitive abilities as a later step because of this hierarchical view of cognition and metacognition. Therefore, metacognitive aspects may be mainly thought of as pertaining to a few students who have higher achievement, but not for all students in natural classroom settings.

\section{Models and Modeling Perspectives on Metacognition}

For a developmental investigation, a theoretical model of metacognition has been developed by adopting the models and modeling perspectives (MMPs) on metacognition (Kim et al., 2013). The MMP has become a productive area for research and practice in science, technology, engineering, and mathematics education (Kim \& Nam, 2017; Lesh \& Zawojewski, 2007; Moore et al., 2015; Moore, Miller, Lesh, Stohlmann, \& Kim, 2013). The MMP evolved from the perspectives of Piaget, Vygotsky, and American Pragmatists such as Charles Sanders Peirce, William James, and John Dewey. Thus, the MMP incorporates constructivist views, as well as modern situated and socio-cultural methods of problem solving, learning, and teaching (Lesh \& English, 2005).

In contrast to the traditional perspectives on metacognition as previously described, the MMP provides new insights into the existing paradigm of research on metacognition as follows (Lesh et al., 2003; Lesh \& Zawojewski, 2007). First, the MMP emphasizes the critical role of holistic conceptual systems that individuals possess in successful problem solving and learning. A conceptual system that a student possesses includes both cognitive (e.g., understanding, skills) and metacognitive (e.g., beliefs, awareness) components. They interactively and bidirectionally influence each other (Lesh et al., 2003). For example, as students increase their understanding, their metacognition is effectively triggered. Likewise, students develop better understanding as their metacognition is actively encouraged.

The MMP operates under the assumption that thinking becomes metacognitive when people change from "thinking with" cognitive components to "thinking about" them, via monitoring and regulating them (Lesh et al., 2003). As a result, the MMP assumes that metacognition and cognition develop in parallel and interactively at the same time, rather than hierarchically. Thus, instruction in metacognition can be embedded in the teaching of mathematics and problem-solving activities (Lesh et al., 2003; Lesh \& Zawojewski, 2007).

Second, an alternative focus of MMP research can be found in the situated, contextual, and social nature of metacognition. The MMP operates under the assumption that metacognition is closely associated with specific contents and contexts because it makes use of individuals' interpretations of 
these contents and contexts rooted in their conceptual systems. In valuing the situated and contextual nature of metacognition, the MMP operates under the assumption that the effectiveness of metacognitive functions frequently differs across problems, and even across the stages of problem solving. This can be explained by the focus of the (sub)tasks varying across problems and changing during the problem-solving processes. For instance, it may be more efficient to brainstorm at the early stages of problem-solving processes as opposed to later stages, such as assessment (Lesh et al., 2003).

The social nature of metacognition is another focal point of the MMP. Research from the MMP frequently examines problem solving while students are involved in collaborative teams, and this research compares teams with individuals. The MMP implies that investigations centering on a team are often a fruitful way to ascertain how one person's mind works in context. Specifically, such investigations help determine how one person's thinking becomes metacognitive (Lesh et al., 2003; Magiera \& Zawojewski, 2011), given that thinking becomes metacognitive when one person begins to function as if she or he were a team of several agents, such as planner, monitor, assessor, and so on, who work together within the person (Lesh et al., 2003).

\section{Multiple Levels of Metacognition}

Based on the MMP, we have reconceptualized metacognition on multiple levels in the theoretical model, focusing on an individual as a unique agent who has access to the sources that trigger metacognition at the individual, social, and environmental levels (Kim et al., 2013). The sources of metacognition, to which an individual has access for eliciting metacognition (e.g., others' conceptual systems), are not active agents, but rather a kind of starting place. In the theoretical model, the term trigger is used to emphasize this starting place that causes individuals to monitor and regulate their cognitive components.

\section{Metacognition Triggered at the Individual Level}

The sources that trigger metacognition at the individual level are individuals' conceptual systems. The internal sources of metacognition are cumulated by the individuals' prior knowledge and experiences, and thus differ in quantity, as well as in quality (Kim et al., 2013). Based on differing conceptual systems, which include both cognitive and metacognitive components, individuals interpret contextual variables, such as particular contents and situations, and their thinking becomes metacognitive (Lesh et al., 2003). Consequently, individuals themselves "trigger" metacognition at the individual level by beginning the work of monitoring or regulating their cognitive components.

\section{Metacognition Triggered at the Social Level}

On the other hand, individuals may go beyond the limits of internal sources of metacognition by having access to external sources of metacognition. One of the external sources is obtained by drawing on the conceptual systems of other individuals, such as peers or teachers. Social interactions comprise the main sources that trigger metacognition at the social level (Kim et al., 2013). Through interactions with peers and teachers, students are often encouraged to retest their current thinking, to monitor their current level of knowledge and understanding, and to detect and correct their misconceptions (e.g., Carr \& Biddlecomb, 1998; Kramarski \& Mevarech, 2003; Smith \& Mancy, 2018).

\section{Metacognition Triggered at the Environmental Level}

Another external source that triggers metacognition originates from the interactions between a person (or persons) and the learning environment (e.g., classroom activities, the types of problemsolving activities, task complexity, and so on). Interactions with the learning environment are also 
the main sources that trigger metacognition, especially at both the individual and social levels (Kim et al., 2013; Volet, Vauras, \& Salonen, 2009). They are potential sources that maximize opportunities for students, either themselves or via others, to begin the work of monitoring or regulating their cognitive components. In particular, social contexts (e.g., team-oriented problem-solving activities) and problem situations requiring students to make their own definitions of qualitative constructs and to negotiate their individual and social meanings are identified as good environmental sources to stimulate students' metacognitive activities, triggered at both the individual and social levels (Kim et al., 2013; Magiera \& Zawojewski, 2011). Figure 1 summarizes how metacognition (or cognition) is triggered on multiple levels.

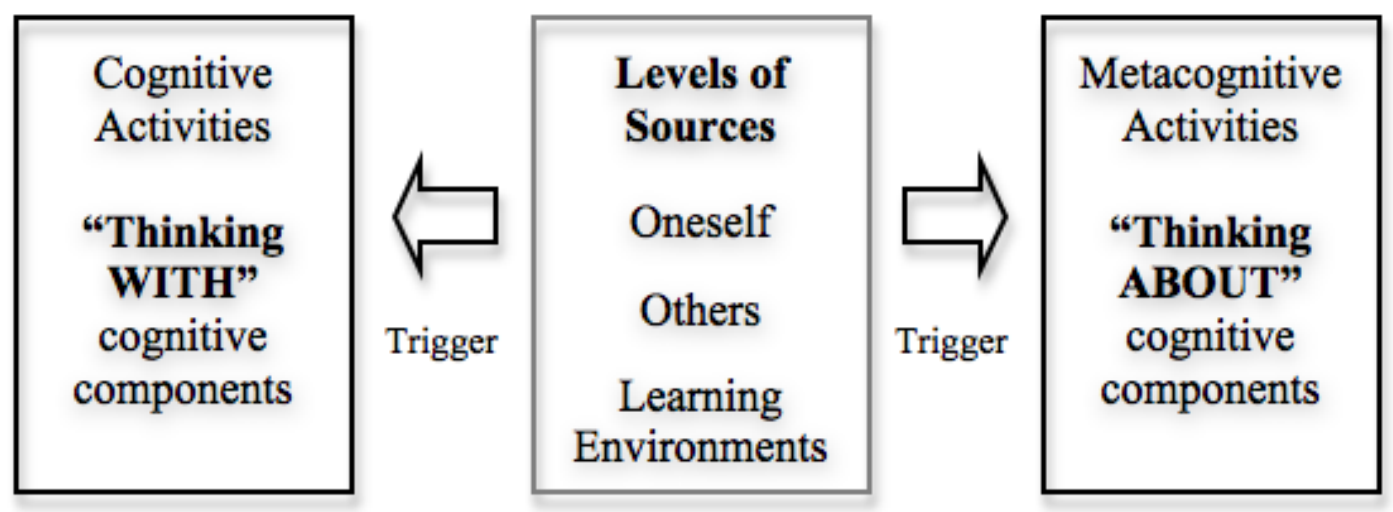

Figure 1. Multiple Levels of Metacognition and Cognition

As mentioned earlier, a multiple-case study is necessary to examine the appropriateness and soundness of the theoretical model for research in metacognition. The current study adopted a multiple-case design involving several student groups to explore students' spontaneous metacognitive activities while working collaboratively on a series of MEAs.

\section{MEAs}

For this study, MEAs were used (a) as an environmental source supporting students' spontaneous metacognitive activities and (b) as a methodological tool for verbal protocol analysis to investigate students' spontaneous metacognitive activities in collaborative problem solving.

\section{MEA as an Environmental Source}

MEAs are complex, open-ended problems, in which students are required to make their own definitions of qualitative constructs (definition building), then to make the qualitative constructs measurable (operationalizing definitions), such as by quantifying, converting, and sampling (e.g., Kim et al., 2013; Kim \& Nam, 2017; Moore et al., 2015). The two problem-solving processes, "definition building" and "operationalizing definitions," encourage students to think about thinking, both in terms of their own and others', and to monitor or regulate likely alternative processes. Specifically, such problem-solving processes engage students in self-assessing their own knowledge and understanding (individual level), as well as in assessing others' (social level). Based on their existing knowledge and prior experience, students need to make judgments regarding their own ways of thinking. These problem-solving processes also engage students in negotiating their individual and social meanings of problem situations or problem-solving processes. 
MEAs are team-oriented problem-solving tasks that require students to verbalize their thoughts spontaneously (according to their own needs or motivations) in natural classroom settings (Kim \& Nam, 2017; Lesh \& Doerr, 2003; Lesh, Hoover, Hole, Kelly, \& Post, 2000; Moore et al., 2013). Engaging in communication and making team agreements are necessary for productive problem solving. These characteristics may enable MEAs to work as an effective environmental source that stimulates students' spontaneous metacognitive activities, triggered at both the individual and social levels. This assumption is supported by the findings of Magiera and Zawojewski (2011). By using five MEAs and self-report methods, they identified and characterized six contexts that stimulated students' spontaneous metacognitive activities triggered at both the individual and social levels. The six contexts - three self-based contexts (seeking personal satisfaction, making experience-based quantitative judgments, and making personal projections) and three social-based contexts (interpreting diverse perspectives, engaging in explanations, seeking mathematical consensus)—are consistent with the characteristics of MEAs.

\section{MEA as a Methodological Tool for Verbal Protocol Analysis}

While working on an MEA, students are engaged in group work in natural classroom settings without any interactions with researchers. The role of teachers as a facilitator and observer avoids any influence on students' solutions. The students are required to verbalize their thoughts only by their own needs (e.g., Kim et al., 2013; Lesh et al., 2000; Lesh \& Lamon, 1992; Moore et al., 2013). The verbal protocols of this problem-solving session can be considered as consistent with an individual's typical behavior during problem solving (Ericsson \& Simon, 1984) and can provide an accurate assessment of metacognitive activity (e.g., Presley, 2000; Veenman, 2005). Thus, MEAs work well as an authentic method for analyzing verbal metacognitive actions (Kim et al., 2013). For that reason, during each problem-solving session in the study, the students should not be given any specific directions besides being asked to actively and collaboratively work on the problem. In particular, the researcher should only be an observer to make field notes, avoiding any interactions with the students.

After recognizing that spontaneity through MEAs has clear advantages, one must also examine MEAs' potential shortcomings for research on metacognition. For example, one might argue that participants' complete thoughts, including metacognitive activities, are never expressed in real communication. Some important thoughts might be kept hidden, as the participant decides what to say and what not to say in a socio-cognitive situation (e.g., "I will not say it because they can't understand me/because they think that I am stupid," etc.). Some degree of incompleteness can be addressed by the collaborative nature of MEAs as mentioned above (Goos \& Galbraith, 1996; Schoenfeld, 1985). Yet MEAs are expected to influence incompleteness to a lesser degree than existing methodological tools (e.g., postinterviews) because students may perceive teachers and researchers as evaluators. Students are less likely to perceive peers as evaluators.

As self-report methods (e.g., inventories), MEAs can be used to systematically explore students' metacognitive activities. Several findings from previous metacognition research were replicated by using MEAs. For example, through the single case study (Kim et al., 2013), we found that the attraction of simplicity interfered with students' spontaneous metacognitive activities in line with Stacey's (1992) warning. Simple ideas produced simple answers quickly, without demonstrating careful thought. We also replicated findings from Artzt and Armour-Thomas (1992) and Stacey (1992), demonstrating that self-confident attitudes can be another factor interfering with metacognitive processes on the social level. In addition, Magiera and Zawojewski (2011) supported findings from previous metacognition research using MEAs, such as the overall predominance of monitoring activities and relative infrequency of regulating activities (Wilson \& Clarke, 2002, 2004), as well as the relative prevalence of monitoring activities triggered at the social level as compared to the individual level (Whitebread, Bingham, Grau, Pasternak, \& Sangster, 2007). 


\section{Research Methodology}

A qualitative multiple-case study was conducted to investigate and describe students' spontaneous metacognitive activities emerging when working together in natural classroom settings (Bogdan \& Biklen, 2003; Creswell, 2006).

\section{Participants}

The study took place in a conveniently selected public suburban middle school in the Midwest of the United States and was conducted in block-scheduled mathematics classes (two consecutive mathematics classes met for approximately $80 \mathrm{~min}$ total, 4 days a week). The participants in this study were seventh-grade students in a higher level mathematics course titled "Algebra With Statistics." The teacher allowed the students to decide upon their own groups before the first problem-solving session, emphasizing that no member change was allowed over the three problemsolving sessions. The group members worked consistently and coherently during each problemsolving session, allowing for sufficient identification of the metacognitive processes in which they engaged. No member change was allowed at this time either.

For each problem-solving session, the students were presented with one MEA described in the next section. Most participants had prior experience with the type of problems selected for the study. In the previous school year, they had participated in an MEA titled "Bigfoot" as part of a science, technology, engineering, and mathematics integration curriculum. The study involved 23 students in seven groups of three to four. Pseudonyms were used to protect the students' identities.

\section{Data Collection}

This study used a series of three MEAs to collect data (see Table 1). The participants collaboratively worked on the three different problem-solving sessions. The primary sources of data for this study were audio transcripts of the student groups, student group solutions to the MEAs (i.e., group letters to imaginary clients), and researcher field notes during the three problem-solving sessions. 
Table 1. Description of the Three Model-Eliciting Activities Used in the Study

\begin{tabular}{|c|c|c|}
\hline Title & Problem and Student Solution Product & Main Strands \\
\hline $\begin{array}{l}\text { Summer } \\
\text { Jobs }\end{array}$ & $\begin{array}{l}\text { Key question: How do you develop a productive management } \\
\text { scheme to decide who to rehire for summer job positions } \\
\text { when reviewing employees' records from last year? } \\
\text { Students are given information about the previous year park } \\
\text { vendors' performance (i.e., numbers of hours they worked, } \\
\text { amount of money they collected, and the overall park } \\
\text { profile). They are asked to analyze the performance of nine } \\
\text { vendors with a goal of developing a system for selecting } \\
\text { three for a full-time and three for a half-time summer job } \\
\text { position. }\end{array}$ & $\begin{array}{l}\text { Number and } \\
\text { operations, } \\
\text { algebra, data } \\
\text { analysis, } \\
\text { statistics, } \\
\text { problem solving, } \\
\text { and } \\
\text { communication }\end{array}$ \\
\hline Volleyball & $\begin{array}{l}\text { Key question: How do you develop a system that will make fair } \\
\text { teams to have more competition in the volleyball summer } \\
\text { camp's tournament based on the information about some of } \\
\text { the players from tryouts and from the coaches? } \\
\text { Students are given numeric and nonnumeric information } \\
\text { about each player. The data include height, vertical leap, } \\
\text { speed, serving percentage, spike results, and the coach's } \\
\text { comments. The students are asked to develop a procedure } \\
\text { for creating equal teams of volleyball players. }\end{array}$ & $\begin{array}{c}\text { Number and } \\
\text { operations, } \\
\text { algebra, data } \\
\text { analysis, } \\
\text { statistics, } \\
\text { problem solving, } \\
\text { and } \\
\text { communication }\end{array}$ \\
\hline $\begin{array}{l}\text { Paper } \\
\text { Airplane }\end{array}$ & $\begin{array}{l}\text { Key question: How do you create a fair judging scheme for a } \\
\text { paper airplane contest when looking for the most accurate } \\
\text { paper airplane and the best floater? } \\
\text { Students are given a set of numeric and visual data recorded } \\
\text { during a paper airplane contest. The data include } \\
\text { information about time in the air, distance traveled, and } \\
\text { accuracy landing. The students are asked to develop a } \\
\text { procedure for selecting the winners of the paper airplane } \\
\text { contest in two categories: Most Accurate and Best Floater. } \\
\text { The problem solvers need to define for themselves each of } \\
\text { these categories before they can select data relevant to } \\
\text { each category and develop a model for analyzing the } \\
\text { relevant performance. }\end{array}$ & $\begin{array}{c}\text { Number and } \\
\text { operations, } \\
\text { algebra, data } \\
\text { analysis and } \\
\text { probability } \\
\text { problem solving, } \\
\text { and } \\
\text { communication }\end{array}$ \\
\hline
\end{tabular}

For the block-scheduled mathematics class periods of $\sim 80 \mathrm{~min}$, each problem-solving session took 2 days, for a total of $\sim 160 \mathrm{~min}$. The three problem-solving sessions were conducted in a natural classroom setting. Each of the three problem-solving sessions captured the collaborative interactions of the student group members as they worked on challenging problems. Each group of three to four students was audio and video recorded to explore student conversations throughout each MEA group activity period. The group conversations of the three to four students in this study were transcribed by using both the audio-and video-recorded data, which provided assurance of the students' identities.

The qualitative data from the multiple-case study allowed us to explore students' spontaneous metacognitive activities while collaboratively solving problems and provided a rich context to identify the circumstances facilitating or interfering with students' spontaneous metacognitive activities. 


\section{Data Analysis}

A finer grained analysis of conversational statements by using two coding strategies-preset and open coding - was conducted by two researchers (an author and a doctoral candidate) to identify the circumstances facilitating or interfering with students' spontaneous metacognitive activities.

The data analysis was conducted by multiple cycles of viewing and reviewing the audio transcripts and video records of the problem-solving sessions, the student group solutions, and the field notes. The two researchers independently coded the data based on the coding schemes used in the single case study (see Kim et al., 2013, for more details) that is consistent with the theoretical model of metacognition on multiple levels.

The coding schemes involved the preset categories (codes): four regulating activities (new idea, reinterpretation, changing strategy, and correcting errors) and six monitoring activities (assessment of knowledge, assessment of understanding, assessment of strategy appropriateness, assessment of progress toward goal, assessment of strategy execution, and assessment of accuracy or sense of result). The types of regulating activity (changing strategy and correcting errors) inherently involve the types of monitoring activity (assessment of strategy appropriateness and assessment of strategy execution), respectively; thus, students' comments identified as changing strategy and correcting errors would be coded as changing strategy/assessment of strategy appropriateness and correcting errors/assessment of strategy execution. In addition, cross-indexing was allowed if needed.

A finer grained analysis of the conversational statements was conducted to identify each student's problem-solving behaviors, monitoring and regulating activities, and to decide on the levels of sources triggering metacognition. Based on the coding results, students' conversational comments were annotated to indicate metacognitive functions, four regulating activities and six monitoring activities, and the levels of sources triggering them.

By focusing on an individual as a unique agent of metacognition, the unit for analyzing verbal protocols was each comment made by an individual. However, the coding decision for each comment was made on the basis of the overall scenario of the students' dialogues within the group, rather than on the basis of each individual statement made. For example, when a student who led a problem-solving process by suggesting a new idea said, "We need to do the money they made over the hours they worked," this comment was coded at the individual level not because of the subject "we," but due to the overall scenario.

Also, nonverbal and verbal cues were considered as important factors in making coding decisions. For example, if students' comments involved some cues of evaluation, such as "Well," "Oh," "I (don't) think," "So, (no) wait," “...don't we?" "Wait, you have to," and so on, the comments could be coded as metacognitive activities because they indicate evaluations occurring. On the other hand, the comment, "So we'd each take a pilot. There are only three pilots and there are three of us. And then you'll average each of these," could be not coded for metacognition because there was no cue of any evaluation based on the overall scenario.

During multiple cycles of data analysis, open coding via annotations, which allowed new categories to emerge from the data (Corbin \& Strauss, 2008; Miles \& Huberman, 1994), was also conducted by the two researchers to identify the circumstances interfering with students' spontaneous metacognitive activities. The Cohen's $K$ coefficient of interrater agreement for coding the data, 0.83 , indicates an acceptable level of reliability (Altman, 1991). The two researchers also reached a consensus on the coding discrepancies via discussion. Figure 2 summarizes the step-by-step process for the data analysis. 


\section{Step 1}

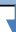

Deciding whether each student's comment was a cognitive activity (if there is no cue of any evaluation or regulation) or a metacognitive activity (if there is a cue of evaluation or regulation),

based on the overall scenario

\section{Example 1}

"So we'd each take a pilot. There are only 3 pilots and there are 3 of us. And then you'll average each of these." (Student S2, Group 5, Paper Airplane, Transcript Segment 72)

\section{Example 2}

"So, I have an idea, Brittany [Student S3]. I don't know if it'll work, but it's an idea. I was thinking that what we could do is we could average each of these for all of the planes." (Student S2, Group 5, Paper Airplane, Transcript Segment 66)

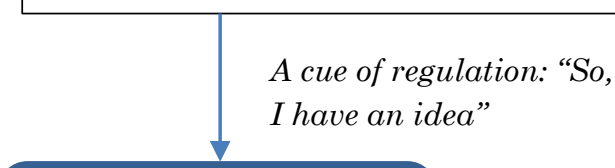

No cue of any evaluation

or regulation based on the

overall scenario

\section{I have an idea"}

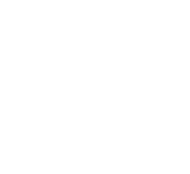

\section{Coding Decision}

Metacognitive activity

\section{Cognitive activity}

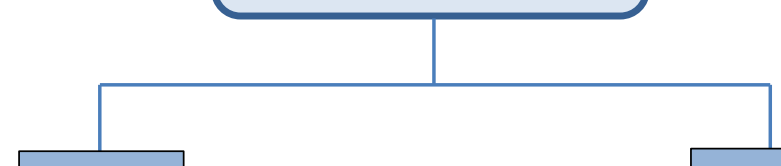

\section{Step 2}

Deciding which level (oneself, others, or learning environments)

triggered the metacognitive activity, after identifying a metacognitive activity, based on the overall scenario

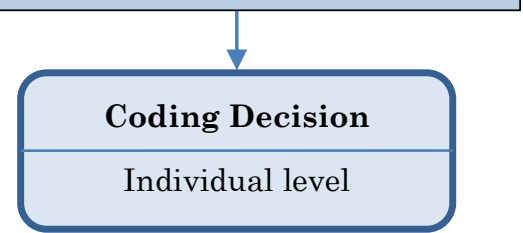

\section{Step 3}

Deciding which metacognitive function it was among the four regulating activities (NI, RI, CS, and $\mathrm{CE}$ ) or the six monitoring activities (A-K, A-U, A-S, A-P, A-E, and A-R), based on the overall scenario

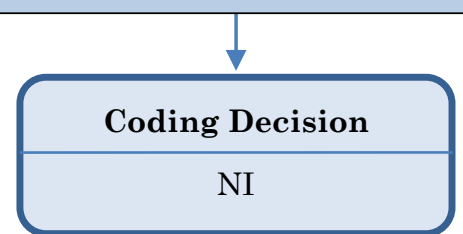

Figure 2. Step-by-Step Process for the Data Analysis. $\mathrm{NI}=$ new idea; $\mathrm{RI}=$ reinterpretation; $\mathrm{CS}=$ changing strategy; $C E=$ correcting errors; $A-K=$ assessment of knowledge; $A-U=$ assessment of understanding; $A-S=$ assessment of strategy appropriateness; $A-P=$ assessment of progress toward goal; $A-E=$ assessment of strategy execution; $A-R=$ assessment of accuracy or sense of result. 


\section{Results and Discussion}

During multiple cycles of data analysis, annotations were made by the two researchers with an agreement to identify the circumstances facilitating or interfering with students' metacognitive activities. Two categories emerged from the annotations describing the circumstances in which metacognitive activity was abandoned. The identified circumstances might interfere with students' spontaneous metacognitive activities themselves. Thus, they might deprive students' chances of achieving more productive outcomes.

\section{Learning Environments in Which Interruptions to Spontaneous Metacognitive Activities Occurred}

First, environmental triggers might sometimes interfere with students' spontaneous metacognitive activities, and might cause less productive outcomes, as illustrated next.

\section{Distorted Function of Mathematics Supplies}

One interesting event that might have interfered with students' metacognition was identified in unexpected circumstances. The existence of mathematics supplies, which were distributed by the teacher, made not only a positive impact but also a negative impact on students' spontaneous metacognitive activities. For example, the existence of a protractor could have made a negative impact on the students' metacognitive activities within Group 3 by causing them to abandon their way of thinking, as illustrated by Student M2's assessment of strategy appropriateness: "It seems like everybody used a protractor. I feel like we did this wrong, even though it is right" (Student M2, Group 3, Paper Airplane, Transcript Segment 212).

There was an example indicating a positive impact of the existence of a calculator on the students' spontaneous metacognitive activities: The accessibility to calculators allowed Student S3 to make a positive evaluation on Student S1's strategy: "Go get a calculator" (Student S3, Group 5, Summer Jobs, Transcript Segment 221). However, the existence of a calculator was also a possible circumstance that might have had a negative impact on the students' spontaneous metacognitive activities, as indicated through several illustrations. For example, Student S3's assessment of strategy appropriateness-"Well, we kind of have to work together because we don't all have a calculator" (Student S3, Group 5, Paper Airplane, Transcript Segment 82)—might have deprived other group members of chances to try different ways of thinking. Another example indicated the possibility of distorted evaluation for strategy appropriateness, and chance interruption for better ideas, as illustrated by Student S2's assessment of strategy appropriateness: "What'd we do if we

didn't use calculators. Then you'd have to figure out another way to do it on the calculators" (Student S2, Group 5, Paper Airplane, Transcript Segment 158).

\section{Other Factors Within Classroom Management Systems}

Another interesting event that might have interfered with students' metacognition was associated with the classroom management system. Several circumstances that might have had a negative impact on the students' spontaneous metacognitive activities were identified in this category. For example, as illustrated at the beginning of this section, periods of time given for problem solving could have had not only a positive impact, but also a negative impact on students' assessment of progress toward their goal for productive problem solving. Additional illustrations related to a negative impact of periods of time given, showing the possibility of chance interruption for students to activate spontaneous metacognitive activities, are "No, the letter [is for] tomorrow. Everything else should be done today" (Student P2, Group 6, Paper Airplane, Transcript Segment 332) and "We're not writing it yet. We still have tomorrow" (Student P4, Group 6, Summer Jobs, Transcript Segment 158). 
Another circumstance that might have had a negative impact on the students' spontaneous metacognitive activities and, thus, might have been able to cause less productive outcomes was associated with student assessment. Although some may argue about the negative effects of grading, the following illustration may indicate that students might not have been motivated to trigger their spontaneous metacognitive activities to get better outcomes if their efforts were not rewarded, based on a sufficient distinction between excellent and poor performance.

Group 1, Paper Airplane MEA, Transcript Lines 302-307

[302] Student H1: We just have to measure the accuracy and best floater. (Assessment of understanding: thinking about a way of thinking; individual level)

[303] Student H3: Watch our way be totally off compared to everyone else's. (Assessment of strategy appropriateness: thinking about a way of thinking; individual level)

[304] Student H2: There is no right answer. (Assessment of strategy appropriateness: thinking about Student H3's way of thinking; social level)

[305] Student H4: Do we get graded on this?

[306] Student H1: No.

[307] Student H3: No.

As the problem solving was approaching its final phrase, Student H3 made an assessment of strategy appropriateness: "Watch our way be totally off compared to everyone else's" (Student H3, Group 1, Paper Airplane, Transcript Segment 303). Then, Student H4 tried to check whether their work on the MEA would be graded or not: "Do we get graded on this?" (Student H4, Group 1, Paper Airplane, Transcript Segment 305). After the conversation, they kept going with their prior strategy, without considering any other alternative ways. The group members did not seem to care about the quality of their solution.

The final example of circumstances that might have interfered with the students' spontaneous metacognitive activities was due to students' homework burden. As already illustrated at the beginning of this section, the homework burden seemed to have a negative impact when the students made an assessment of strategy appropriateness, by leading them to abandon a more careful assessment for productive problem solving, as follows:

Group 1, Paper Airplane MEA, Transcript Lines 363-371

[363] Student H3: How about how long it was in the air past a certain height, does it give us the heights? Nope. (New idea: thinking about a way of thinking; individual level)

[364] Student H1: How long it was in the air one foot above the ground? (Assessment of understanding: thinking about Student H3's way of thinking; social level)

[365] Student H3: Yeah. (Assessment of understanding: thinking about Student H1's way of thinking; social level)

[366] Student H4: You just got to remember we don't get homework when we do this, so it's all worth it. (Assessment of strategy appropriateness: thinking about Student H3's way of thinking; social level)

[367] Student H2: Exactly. (Assessment of strategy appropriateness: thinking about Student H4's way of thinking; social level)

[Irrelevant conversation]

[370] Student H1: We're pretty much done. (Assessment of progress towards goal: thinking about a way of thinking; individual level)

[371] Student H3: We're done? That was easier. I think we were definitely over thinking it. (Assessment of progress towards goal: thinking about Student H1's way of thinking; social level) 
When the students worked on operationalizing the definition for the best floater, in which they needed to quantify what "best floating" meant for themselves, Student H3 herself triggered her new idea: "How about how long it was in the air past a certain height, does it give us the heights? Nope" (Student H3, Group 1, Paper Airplane, Transcript Segment 363). Then, the new idea triggered Student H1's assessment of her understanding of Student H3's way of thinking at the social level: "How long was it in the air one foot above the ground? (Student H1, Group 1, Paper Airplane, Transcript Segment 364). Afterward, the homework burden made a negative impact on the students' spontaneous metacognitive activities by causing Student H4 and Student H2's unsuitable assessment of strategy appropriateness: "You just got to remember we don't get homework when we do this, so it's all worth it" (Student H4, Group 1, Paper Airplane, Transcript Segment 366) and "Exactly" (Student H2, Group 1, Paper Airplane, Transcript Segment 367). Without any additional assessment, the students tried to conclude the problem solving.

\section{Social Interactions From Which Interruptions to Spontaneous Metacognitive Activities Occurred}

As did environmental triggers, social triggers might also sometimes interfere with students' spontaneous metacognitive activities and, thus, might interrupt students from achieving more productive outcomes.

\section{Teachers' Inappropriate Intervention}

Undoubtedly, the role of teachers was critical in eliciting or confounding students' metacognitive activities. One circumstance that might have interfered with students' spontaneous metacognitive activities came from the teacher's inappropriate intervention. It was well illustrated by the following examples.

At the beginning of the problem-solving session of the Paper Airplane MEA, when the teacher led a class discussion to share students' answers to the readiness questions, the teacher mentioned,

I have protractors that I will hand out, which will help you to measure the angles on the graphs if you want to do that. So, you can draw straight lines and find the actual angles for each of these points plotted. That will better help you determine how accurate the throw actually was. (Teacher, Group 1, Paper Airplane, Transcript Segment 96)

This guided direction from the teacher reflecting his own way of thinking seemed to unintentionally interfere with students' spontaneous metacognitive activities by reducing chances for the students to work on definition building, in which they needed to define what "accurate" meant for themselves. For example, Group 2 depended on the teacher's way of thinking without any evaluation by using protractors. Many groups also spent a substantial amount of time measuring the angles on the graphs, even though it was unnecessary because they had already been given the numeric data.

Even though some students indicated this point, such as "Okay he told me what to do. This is positive, and this is negative. Okay, so ... (mumbling)... so like this already has all the information why are we even doing this? Okay this is positive and this is negative" (Student W1, Group 7, Paper Airplane, Transcript Segment 57), the teacher adhered to his way of thinking and seemed to enforce it with the students, as illustrated by the following statements: "Some people were asking why they needed to measure the angles with a protractor if they already gave us the degrees. Well, here's why" (Teacher, Group 3, Paper Airplane, Transcript Segment 157) and

Which one of those is $16^{\circ}$ ? Can you tell by looking at it? Just by looking at it without measuring it? No, that is why I gave you the protractors to measure. Now, you might think that's really tedious and will take me forever. Well, I have extras in case your group wants 
more than one. Do you feel better about protractors and how to find the angles? (Teacher, Group 3, Paper Airplane, Transcript Segment 160)

\section{A Negative Impact of Mixed-Gender Groups}

When collaboratively working in a group, problem-solving performance might be affected by many factors, such as group size and group composition. These factors might influence the quality of one's interactions with others, which also elicited or confounded metacognitive activities. In addition to the teacher's inappropriate intervention, another circumstance identified in the study that might have interfered with the students' spontaneous metacognitive activities was associated with the group composition in terms of gender, that is, mixed-gender grouping.

This study involved two mixed-gender groups among seven, which had been formed by the students themselves. As mentioned before, the teacher allowed students to decide upon their own groups before the first problem-solving session, emphasizing that no member change was allowed over the three problem-solving sessions. The mixed-gender groups were Group 2, in which two girls (Students K2 and K3) and one boy (Student K1) worked together, and Group 4, in which one girl (Student R3) and two boys (Students R1 and R2) worked together. The results from the data analysis showed the relatively small quantities of transcript segments, which were identified as metacognitive activities from Group 2 (a total of 256 transcript segments) and Group 4 (a total of 216 transcript segments) compared to those from Groups 1, 3, 5, 6, and 7 (a total of 603, 749, 844, 1,059, and 342 transcript segments, respectively). The differences in the quantity of metacognitive activities identified from each group were directly due to the different quantities of audio transcripts-how often they verbalized their thoughts and, thus, how often they revealed their verbal metacognitive actions. Also, the differences in the quantity of the audio transcripts indicated different degrees to which group members were engaged in collaboration to solve the problems. Consequently, the relatively small quantities of transcript segments that were identified as metacognitive activities from the two mixed-gender groups might indicate a negative impact of mixed-gender grouping on students' spontaneous metacognitive activities by causing lower levels of interaction and cooperation.

\section{A Lack of Collaborative Working Skills}

The final example of circumstances that might have interfered with the students' spontaneous metacognitive activities for productive problem solving involved a lack of collaborative working skills in negotiating individual and social meanings about problems, making a common goal, and deciding a strategy to successfully attain that goal. The problem-solving processes of Group 6 working on the Summer Jobs MEA aptly illustrated this circumstance. Figure 3 shows the final letter from Group 6 to an imaginary client in the MEA. The group solution to the MEA directly illustrated how a lack of collaborative working skills could have caused disconnections in group interaction, which might have interrupted the students' spontaneous metacognitive activities for productive problem solving. 


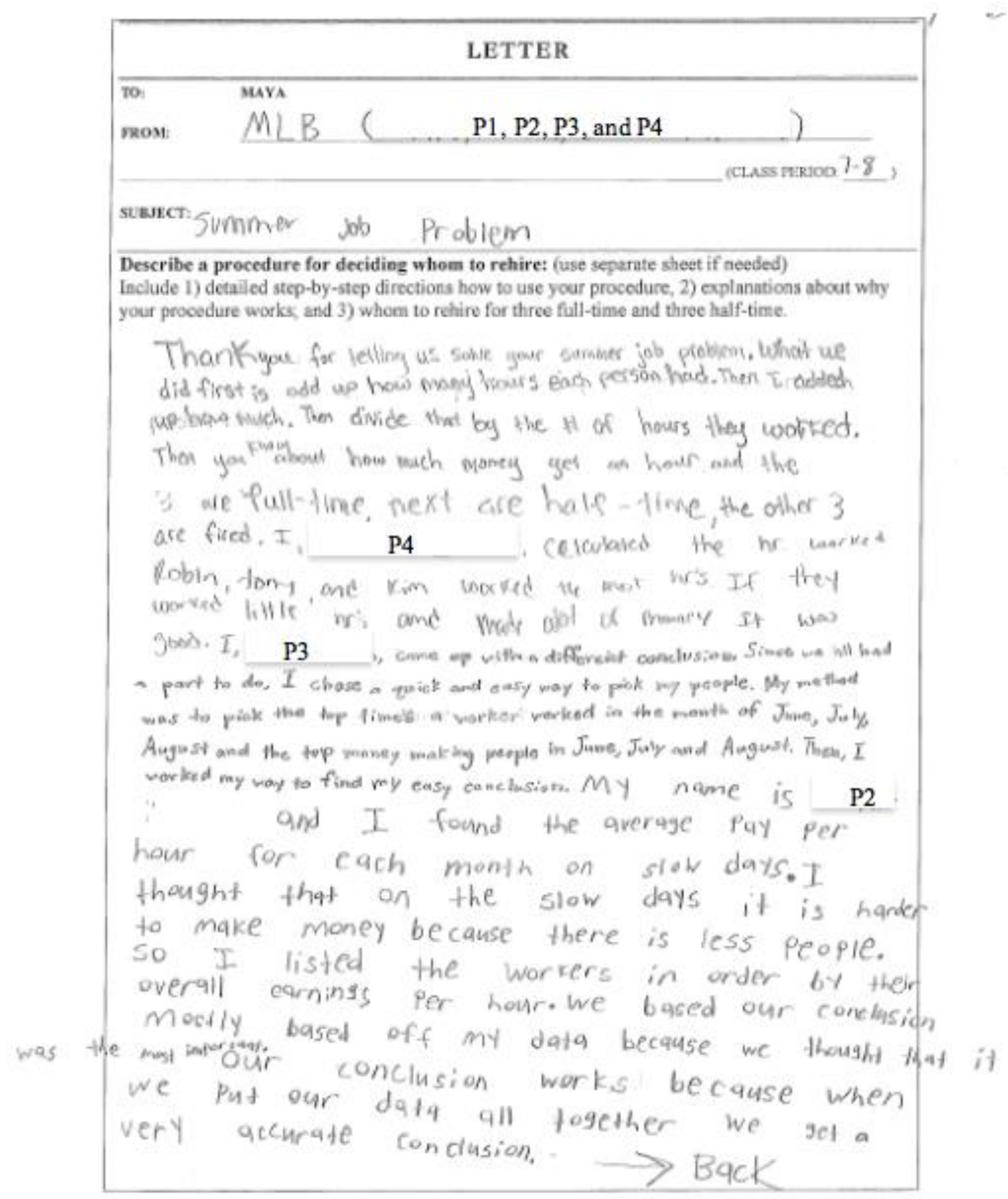

Figure 3. Letter From Group 6 (Solution to the Summer Jobs Model-Eliciting Activity) 
As shown in the letter, each student within Group 6 reported individual solutions by using different strategies in the letter, rather than a group solution, such as "I, P3, came up with a different conclusion...My method was to pick the top times a worker worked in the month of June, July, August..." and "My name is P2 and I found the average pay per hour for each month on slow days."

Throughout the problem solving, the students' metacognitive activities were often interrupted due to a lack of agreement on a strategy as a whole group to attain a common goal. The students' assessment of progress toward the goal, strategy execution, and accuracy or sense of result was often triggered separately, based on different criteria for different goals. Sometimes the students worked in pairs, but infrequently in a whole group, indicating a lack of collaboration, which might have interfered with students' spontaneous metacognitive activities for productive problem solving.

\section{Implications and Future Directions}

The current study aims to contribute to the still underdeveloped progress in research on metacognition, which lacks a theoretical base and an authentic method to observe and analyze metacognition and currently has a weak impact on school practice. The first contribution of this study is in response to the need for a developmental investigation of how an individual's mind works in context, with the expectation for potential application to school practice (Lesh \& Zawojewski, 2007; Schoenfeld, 1999).

The second major contribution of this study is the confirmation of findings from a previous single case study (Kim et al., 2013). First, the current multiple-case study has illustrated how reconceptualizing metacognition on multiple levels—individual, social, and environmental—makes an in-depth investigation of the development of students' metacognitive abilities possible. Second, it has demonstrated how MEAs can be a substitute for self-report methods, which have been used in most research on metacognition, using the theoretical model of metacognition on multiple levels. Through providing detailed accounts of data analysis procedures and a large sample of the identified metacognitive activities, the current multiple-case study has illustrated that MEAs could work as a method for verbal protocol analysis. MEAs provide access to students' mental processesparticularly, metacognitive activities.

Finally, the third major contribution of this study is the identification of circumstances in which metacognitive activity is abandoned. Whereas Goos (2002) identified the circumstances related to metacognitive failures, in which less successful outcomes are produced-described as metacognitive blindness, metacognitive vandalism, and metacognitive mirage - this study has identified the circumstances that might interfere with students' spontaneous metacognitive activities themselves; thus, they might deprive students' chances of achieving more productive outcomes. The first category includes a distorted function of mathematics supplies (e.g., calculators and protractors), periods of time given for problem solving, no grade points, and the homework burden. The second category involves the teacher's inappropriate intervention, which is in line with a lack of teacher readiness (Alzahrani, 2017), mixed-gender groups, and a lack of collaborative working skills supported by the opinion of Alzahrani (2017) and Smith and Mancy (2018).

The findings may need to be verified in additional studies. However, it would be useful and valuable enough to consider the circumstances to create metacognitive learning environments that support students' spontaneous development of metacognitive abilities. As a result, the current study informs researchers and practitioners how to effectively encourage students' metacognition, with the expectation to improve their problem-solving achievement.

First, when designing metacognitive learning environments, it is necessary to consider the minimization of circumstances that interfere with students' spontaneous metacognitive activities. 
For example, teachers can minimize the distorted function of mathematics supplies and manipulatives, which was identified as one of the circumstances interfering with students' spontaneous metacognitive activities in the current study, by equipping an arsenal of mathematics supplies and manipulatives in a corner of the classroom where students can stop by based on their own needs, rather than handing them out. In addition, teachers need to avoid comments or questions that steer their students toward a particular solution reflecting the teachers' own way of thinking, which was identified as another circumstance interfering with students' spontaneous metacognitive activities in the current study.

Second, to engage students in active, higher order learning, it is necessary to develop effective instructional methods to integrate circumstances supporting students' spontaneous development of metacognitive abilities into existing curricula. The current study has illustrated how MEAs work as an environmental source to stimulate students' spontaneous metacognitive activities in a natural classroom setting. MEAs effectively establish both individual-based and social-based contexts that stimulate students' spontaneous metacognitive activities triggered at the individual and social levels, respectively. They involve a set of data via multiple representations and are inherently mathematical structures-oriented. In particular, MEAs require students to define a qualitative construct (definition building) and to make a qualitative construct measurable to formalize the goal of a problem (operationalizing definitions).

This study involved multiple-case studies of 23 students in seven groups of three to four. Students worked collaboratively on three different problem-solving sessions during an academic year. Despite extensive research, reasonable caution must be exercised in generalizing the results of this study. Yet this study's identified factors may be sufficient to design metacognitive learning environments.

Another limitation of this study might be the narrow range of metacognitive activities identified at the environmental level, which might originate from the narrow range of problem-solving tasks used. This possible limitation provides opportunities for future research by suggesting studies to investigate what types of problems (beyond MEAs) and learning environments elicit various levels of metacognition. In addition, the current study did not examine the different levels of complexity in the problem-solving tasks as environmental sources for triggering metacognition, which could also be an area for further research.

By using the theoretical model of metacognition on multiple levels, further research is also needed to understand what types of environments (e.g., textbooks, curricula, technology, etc.) effectively encourage metacognition on the individual and social levels and what types of social sources (e.g., role of the teacher, heterogeneous and homogeneous groups, etc.) effectively encourage metacognition. Finally, the empirical identification of two categories for circumstances in which metacognitive activity is abandoned provides a springboard for continued investigation.

\section{References}

Altman, D. G. (1991). Practical statistics for medical research. London, United Kingdom: Chapman and Hall.

Alzahrani, K. S. (2017). Metacognition and its role in mathematics learning: An exploration of the perceptions of a teacher and students in a secondary school. International Electronic Journal of Mathematics Education, 12, 521-537.

Artzt, A. F., \& Armour-Thomas, E. (1992). Development of a cognitive-metacognitive framework for protocol analysis of mathematical problem solving in small groups. Cognition and Instruction, 9, 137-175. 
Bayat, S., \& Tarmizi, R. A. (2010). Assessing cognitive and metacognitive strategies during algebra problem solving among university students. Procedia Social and Behavioral Sciences, 8, 403410.

Bogdan, R., \& Biklen, S. (2003). Qualitative research for education: An introduction to theory and methods (4th ed.). Needham Heights, MA: Allyn and Bacon.

Bonnett, V., Yuill, N., \& Carr, A. (2017). Mathematics, mastery and metacognition: How adding a creative approach can support children in maths. Educational and Child Psychology, 34, 8393.

Bransford, J. D., Brown, A. L., \& Cocking, R. R. (2000). How people learn: Brain, mind, experience, and school. Washington, DC: National Academy Press.

Callan, G. L., Marchant, G. J., Finch, W. H., \& German, R. L. (2016). Metacognition, strategies, achievement, and demographics: Relationships across countries. Educational Sciences: Theory \& Practice, 16, 1485-1502.

Campione, J. C., Brown, A. L., \& Connell, M. L. (1989). Metacognition: On the importance of understanding what you are doing. In R. I. Charles \& E. A. Silver (Eds.), The teaching and assessing of mathematical problem solving (pp. 93-114). Reston, VA: The National Council of Teachers of Mathematics.

Carr, M., \& Biddlecomb, B. (1998). Metacognition in mathematics: From a constructivist perspective. In D. J. Hacker, J. Dunlosky, \& A. C. Graesser (Eds.), Metacognition in educational theory and practice. Mahweh, NJ: Erlbaum.

Corbin, J., \& Strauss, A. (2008). Basics of qualitative research (3rd ed.). Thousand Oaks, CA: Sage.

Creswell, J. (2006). Qualitative inquiry and research design: Choosing among five traditions (2nd ed.). Thousand Oaks, CA: Sage.

Ericsson, K. A., \& Simon, H. A. (1984). Protocol analysis: Verbal reports as data. Cambridge, MA: Bradford Books/MIT Press.

Goos, M. (2002). Understanding metacognitive failure. Journal of Mathematical Behavior, 21, 283302.

Goos, M., \& Galbraith, P. (1996). Do it this way! Metacognitive strategies in collaborative mathematical problem solving. Educational Studies in Mathematics, 30, 229-260.

Goos, M., Galbraith, P., \& Renshaw, P. (2002). Socially mediated metacognition: Creating collaborative zones of proximal development in small group problem solving. Educational Studies in Mathematics, 49, 193-223.

Kim, Y. R., \& Nam, Y. (2017). Exploring American Indian students' problem-solving propensity in the context of culturally relevant STEM topics. Journal of the Korean Society of Earth Science Education, 10, 1-16.

Kim, Y. R., Park, M. S., Moore, T. J., \& Varma, S. (2013). Multiple levels of metacognition and their elicitation through complex problem-solving tasks. Journal of Mathematical Behavior, 32, 377-396.

Kramarski, B., \& Mevarech, Z. R. (2003). Enhancing mathematical reasoning in the classroom: The effects of cooperative learning and metacognitive training. American Educational Research Journal, 40, 281-310.

Lesh, R., \& Doerr, H. M. (2003). Foundations of a models and modeling perspective on mathematics teaching, learning, and problem solving. In R. Lesh \& H. M. Doerr (Eds.), Beyond 
constructivism: Models and modeling perspectives on mathematics problem solving, learning, and teaching (pp. 3-33). Mahwah, NJ: Erlbaum.

Lesh, R., \& English, L. D. (2005). Trends in the evolution of models \& modeling perspectives on mathematical learning and problem solving. ZDM: The International Journal on Mathematics Education, 37, 487-489.

Lesh, R., Hoover, M., Hole, B., Kelly, A., \& Post, T. (2000). Principles for developing thoughtrevealing activities for students and teachers. In A. Kelly \& R. Lesh (Eds.), Research design in mathematics and science education (pp. 591-646). Mahwah, NJ: Erlbaum.

Lesh, R., \& Lamon, S. (1992). Assessing authentic mathematical performance. In R. Lesh \& S. J. Lamon (Eds.), Assessment of authentic performance in school mathematics (pp. 17-62). Washington, DC: American Association for the Advancement of Science.

Lesh, R., Lester, F. K., \& Hjalmarson, M. (2003). A models and modeling perspective on metacognitive functioning in everyday situations where problem solvers develop mathematical constructs. In R. Lesh \& H. M. Doerr (Eds.), Beyond constructivism: Models and modeling perspectives on mathematics problem solving, learning, and teaching (pp. 383403). Mahwah, NJ: Erlbaum.

Lesh, R., \& Zawojewski, J. S. (2007). Problem solving and modeling. In F. K. Lester, Jr. (Ed.), Second handbook of research on mathematics teaching and learning (pp. 763-804). Reston, VA: National Council of Teachers of Mathematics.

Magiera, M. T., \& Zawojewski, J. S. (2011). Characterizations of social-based and self-based contexts associated with students' awareness, evaluation, and regulation of their thinking during small-group mathematical modeling. Journal for Research in Mathematics Education, 42, $486-520$.

Miles, M. B., \& Huberman, A. M. (1994). Qualitative data analysis. Thousand Oaks, CA: Sage.

Moore, T. J., Guzey, S. S., Roehrig, G. H., Stohlmann, M., Park, M. S., Kim, Y. R., Callender, H. L., \& Teo, H. J. (2015). Changes in faculty members' instructional beliefs while implementing model-eliciting activities. Journal of Engineering Education, 104, 279-302.

Moore, T. J., Miller, R. L., Lesh, R. A., Stohlmann, M. S., \& Kim, Y. R. (2013). Modeling in engineering: The role of representational fluency in students' conceptual understanding. Journal of Engineering Education, 102, 141-178.

Muir, T., Beswick, K., \& Williamson, J. (2008). "I'm not very good at solving problems": An exploration of students' problem solving behaviors. Journal of Mathematical Behavior, 27, $228-241$.

National Council of Teachers of Mathematics. (2000). Principles and standards for school mathematics. Reston, VA: The National Council of Teachers of Mathematics.

Özcan, Z. C. (2016). The relationship between mathematical problem-solving skills and selfregulated learning through homework behaviours, motivation, and metacognition. International Journal of Mathematical Education in Science and Technology, 47, 408-420.

Presley, M. (2000). Development of grounded theories of complex cognitive processing: Exhaustive within-and between study analyses of think-aloud data. In G. Schraw \& J. C. Impara (Eds.), Issues in the measurement of metacognition (pp. 262-296). Lincoln, NE: Buros Institute of Mental Measurements.

Radmehr, F., \& Drake, M. (2017). Exploring students' mathematical performance, metacognitive experiences and skills in relation to fundamental theorem of calculus. International Journal of Mathematical Education in Science and Technology, 48, 1043-1071. 
Sahin, S. M., \& Kendir, F. (2013). The effect of using metacognitive strategies for solving geometry problems on students' achievement and attitude. Educational Research and Reviews, 8, $1777-1792$.

Schoenfeld, A. H. (1985). Mathematical problem solving. Orlando, FL: Academic Press.

Schoenfeld, A. H. (1987). What's all the fuss about metacognition? In A. Schoenfeld (Ed.), Cognitive science and mathematics education (pp. 189-215). Hillsdale, NJ: Erlbaum.

Schoenfeld, A. H. (1992). Learning to think mathematically: Problem solving, metacognition, and sense-making in mathematics. In D. Grouws (Ed.), Handbook for research on mathematics teaching and learning (pp. 334-370). New York, NY: MacMillan.

Schoenfeld, A. H. (1999). Looking towards the 21st century: Challenges of educational theory and practice. Educational Researcher, 28, 4-14.

Schraw, G. (1998). Promoting general metacognitive awareness. Instructional Science, 26, 113-125.

Smith, J. M., \& Mancy, R. (2018). Exploring the relationship between metacognitive and collaborative talk during group mathematical problem-solving: What do we mean by collaborative metacognition? Research in Mathematics Education, 20, 14-36.

Stacey, K. (1992). Mathematical problem solving in groups: Are two heads better than one? Journal of Mathematical Behavior, 11, 261-275.

Veenman M. J., (2005). The assessment of metacognitive skills: What can be learned from multimethod designs? In C. Artelt \& B. Moschner (Eds.), Lernstrategien und metakognition: Implikationen fur forschung und praxis [Learning strategies and metacognition: Implications for research and practice] (pp. 3-29). Berlin, Germany: Waxmann.

Volet, S., Vauras, M., \& Salonen, P. (2009). Self- and social regulation in learning contexts: An integrative perspective. Educational Psychologist, 44, 215-226.

Whitebread, D., Bingham, S., Grau, V., Pasternak, D. P., \& Sangster, C. (2007). Development of metacognition and self-regulated learning in young children: Role of collaborative and peerassisted learning. Journal of Cognitive Education and Psychology, 6, 433-455. doi:10.1891/194589507787382043

Wilson, J., \& Clarke, D. (2002). Monitoring mathematical metacognition. Paper presented at the Annual Meeting of the American Educational Research Association, New Orleans, LA, April $1-5$.

Wilson, J., \& Clarke, D. (2004). Towards the modelling of mathematical metacognition. Mathematics Education Research Journal, 16, 25-48. 
The Journal of Educational Research and Practice provides a forum for studies and dialogue that allows readers to better develop social change in the field of education and learning. Journal content may focus on educational issues of all ages and in all settings. It also presents peer-reviewed commentaries, book reviews, interviews of prominent individuals, and additional content. The objectives: We publish research and related content that examines current relevant educational issues and processes aimed at presenting readers with knowledge and showing how that knowledge can be used to impact social change in educational or learning environments. Additional content provides an opportunity for scholarly and professional dialogue regarding that content's usefulness in expanding the body of scholarly knowledge and increasing readers' effectiveness as educators. The journal also focuses on facilitating the activities of both researcher-practitioners and practitioner-researchers, providing optimal opportunities for interdisciplinary and collaborative thought through blogging and other communications.

Walden University Publishing: http://www.publishing.waldenu.edu 